\title{
Potential degradation of hazardous dye Congo red by nano- metallic particles synthesized from the automobile shredder residue
}

\author{
Jiwan Singh $^{1} \cdot$ Ajay S. Kalamdhad ${ }^{2} \cdot$ Janardhan Reddy Koduru $^{3}$
}

Received: 9 February 2017/ Accepted: 24 June 2017/Published online: 3 July 2017

(C) Springer International Publishing AG 2017

\begin{abstract}
This study was carried out on the degradation of Congo red (CR) in an aqueous solution by nano-metallic particles (NMPs). The NMPs were synthesized from the leachate of automobile shredder residue. Scanning electron microscopy was performed to analyze the morphology of particles. Fourier transform infrared spectroscopy (FTIR) was also done to demonstrate the possibility and changes of various functional groups before and after the reaction of NMPs. The effect of the dosages of NMPs, $\mathrm{pH}$ values of solution, concentrations of $\mathrm{CR}$ and $\mathrm{H}_{2} \mathrm{O}_{2}$ on CR degradation was studied. The results of the present study confirm that the $\mathrm{CR}$ degradation rate was improved by increasing the dosages of NMPs and $\mathrm{H}_{2} \mathrm{O}_{2}$ up to certain limit and then reduced gradually. However, degradation rate was reduced by raising the $\mathrm{pH}$ values and concentration of $\mathrm{CR}$. The pseudo-second-order kinetics was found to be suitable for the degradation of CR by NMPs under Fenton-like process.
\end{abstract}

Keywords NMPs $\cdot$ CR $\cdot$ Kinetics $\cdot$ Mechanism · Degradation

Jiwan Singh

jiwansingh95@gmail.com

$\square$ Janardhan Reddy Koduru reddyjchem@gmail.com

1 Department of Environmental Science, Babasaheb Bhimrao Ambedkar University, Lucknow 226025, India

2 Department of Civil Engineering, Indian Institute of Technology Guwahati, Guwahati, Assam 781039, India

3 Department of Environmental Engineering, Kwangwoon University, Seoul 139-701, Republic of Korea

\section{Introduction}

The presence of reactive azo dyes in water stream can pose serious environmental problems. These dyes are released from the textile and dyeing industries [1]. Azo dyes have been predicted as potential genotoxic and carcinogenic chemical [2]. Approximately $15 \%$ of the dyes are lost during the dyeing process, and then, it released into environment [3]. Congo red (CR) is one of most widely used dye in the textile industries. This dye cannot be efficiently decolorized mainly because of presence of many benzene rings in their structure. Dyes removal from wastewater has been widely studied to reduce its environmental impact. There are different types of techniques available, which are adsorption [4], ozonation [5], Fenton-like degradation [6] and photocatalysis [7]. Fenton-like degradation is a rapid and cost-effective approach, and this is also simple to implant for the industrial scale to remove dyes from the wastewater before discharging into the environment. In the Fenton-like process, hydroxyl radicals are produced by the oxidation using hydrogen peroxide [8]. Currently, nanoparticles have been applied for azo dye removal; these particles are zero-valent iron $\left(\mathrm{Fe}^{0}\right)$ [9] and bimetallic nanoparticle, such as Fe/Ni [10]. Adsorptive removal of CR has been studied by some researchers [11-13]. Recently, nano-metallic particles (NMPs) have been considered as a promising agent to treat the organic pollutants from the wastewater [8, 14]. However, application of NMPs for degradation of reactive azo dye (CR) is still limited.

Therefore, the present study was carried on the removal of CR by NMPs in the presence of hydrogen peroxide. NMPs were recovered from the fine fraction of automobile shredder residue (ASR). This has been considered that ASR is highly contaminated with heavy metals $[15,16]$. In many countries, ASR waste is dumping into landfills, 
which may increase the risk of ground water pollution $[15,17]$. The objective of the study was to treat the dye containing wastewater by applying NMPs (recovered from the leachate of ASR).

\section{Materials and methods}

The analytical grade chemicals were used in this work. A Congo red $\left(\mathrm{C}_{32} \mathrm{H}_{22} \mathrm{~N}_{6} \mathrm{Na}_{2} \mathrm{O}_{6} \mathrm{~S}_{2}\right)$ sodium borohydride $\left(\mathrm{NaBH}_{4}\right)$, hydrogen peroxide $\left(\mathrm{H}_{2} \mathrm{O}_{2}\right)$ and hydrochloric acid $(\mathrm{HCl})$ were supplied by Samchun Pure Chemicals Co. Ltd. (South Korea). Figure 1 shows the molecular structure of Congo red.

The details of the leaching of metals and recovery of NMPs from the ASR have been given in our previous study [14]. The recovery of NMPs was conducted at $\mathrm{pH} 7$ of leachate solution through reduction method by using sodium borohydride $\left(\mathrm{NaBH}_{4}\right)$. The experiment on $\mathrm{CR}$ degradation by NMPs was carried out in conical flasks of $250 \mathrm{~mL}$ at $25{ }^{\circ} \mathrm{C}$ in a water bath shaker (SWB-35, Hanyang Scientific equipment Co., Ltd., South Korea) at $60 \mathrm{rpm}$. A $100 \mathrm{~mL}$ of CR solution was taken in flasks, and then, suitable amount of NMPs $(0.1 \mathrm{~g} / \mathrm{L}$, except dose study) and $\mathrm{H}_{2} \mathrm{O}_{2}\left(50 \mathrm{mM}\right.$, except $\mathrm{H}_{2} \mathrm{O}_{2}$ concentration) was added to solution. Experiment was also carried out at different values of $\mathrm{pH}(\mathrm{pH} 2,3,4$ and 5) of the CR solution, and the $\mathrm{pH}$ of CR solution was maintained with $0.1 \mathrm{~N} \mathrm{HCl}$ and $0.1 \mathrm{~N}$ $\mathrm{NaOH}$. A solution of natural $\mathrm{pH}(6.5)$ also checked the CR degradation by NMPs. To measure the remaining CR concentration in solution, a $2 \mathrm{~mL}$ of sample was taken at various time intervals and then filtered through a $0.25-\mu \mathrm{m}-$ size filter paper.

To determine the residual concentration of CR, UVVisible spectrophotometer (UV 1601, Shimadzu) was used at a maximum wavelength $\left(\lambda_{\max }\right)$ of $495 \mathrm{~nm}$. The scanning electron microscope (SEM; S-4300CX; Hitachi, Japan) was applied to analyze morphology of NMPs. A Fourier transform infrared (FTIR) spectrophotometer (ISF 66/S, Bruker) was used to describe the functional groups on NMPs before and after reaction. X-ray diffraction (XRD) studies of the NMPs were analyzed using a D/Max-2500 diffractometer (Rigaku, Japan).

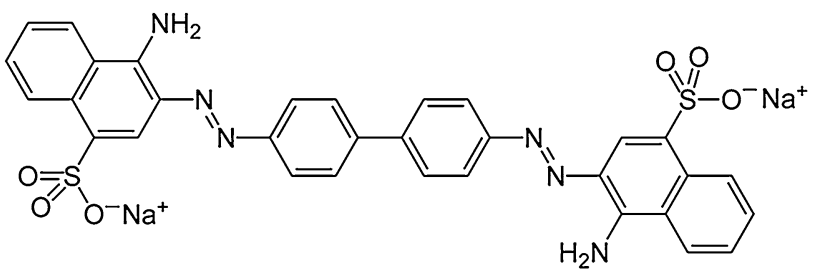

Fig. 1 The molecular structure of hazardous dye Congo red (CR)
The rate of CR degradation by NMPs was determined by a pseudo-first-order reaction model [14],

$\ln \left(C_{t} / C_{0}\right)=-k_{1} t$

where $C_{0}$ is the initial concentration of $\mathrm{CR}(\mathrm{mg} / \mathrm{L}), C_{t}$ represents residual concentration of $\mathrm{CR}$ at time $t(\mathrm{~min})$, and $k_{1}$ is the pseudo-first-order rate constant $\left(\mathrm{min}^{-1}\right)$.

The removal of the CR by NMPs was also studied by a pseudo-second-order reaction kinetics [18],

$1 / C_{t}=\left(1 / C_{0}\right)+k_{2} t$

The slope of the plot between $1 / C_{t}$ and time yields the pseudo-second-order rate constant $k_{2}$.

\section{Results and discussion}

\section{Characterization of NMPs}

Figure 2a represents a SEM image of the prepared NMPs. The results of the SEM analysis revealed that NMPs are not in spherical shape. Most of nanoparticles display a small clumping; this may be due to magnetic interaction by $\mathrm{Fe}$ present in NMPs [19]. The diameter of the NMPs was observed $\leq 100 \mathrm{~nm}$. These NMPs tended to aggregate together to form chain structures, which might be due to the magnetic interaction between small particles [20]. As shown in Table $1, \mathrm{Fe}$ was the most dominated element (54.65\%) followed by carbon (26.47\%), Zn (11.72\%), and $\mathrm{Al}$ and $\mathrm{Cu}(3.02 \%)$. However, $\mathrm{Ni}, \mathrm{Pb}$ and $\mathrm{Mn}$ were found to be in trace quantity.

FTIR spectra of NMPs before and after reaction with CR are shown in Fig. 2b. The peak was observed at $1396.7 \mathrm{~cm}^{-1}$; this peak specifies the presence of metals oxides $(\mathrm{M}-\mathrm{O})$ bands on the surface of NMPs. However, after reaction this peak was found to be slightly smaller and also shifted at $1413.6 \mathrm{~cm}^{-1}$. M-O band could indicate the $\mathrm{M}_{2} \mathrm{O}_{3}$ and $\mathrm{M}_{3} \mathrm{O}_{4}$ which designated partial oxidation of NMPs $[14,21]$. The FTIR spectra of NMPs exhibited broaden bands at $3298 \mathrm{~cm}^{-1}$, which describe the $\mathrm{O}-\mathrm{H}$ stretching [14]. After reaction, this peak was widen and shifted to $3206.5 \mathrm{~cm}^{-1}$. The peak at $1647.9 \mathrm{~cm}^{-1}$ represents the $\mathrm{O}-\mathrm{H}$ stretching; however, intensity of this peak was improved and shifted to $1619.02 \mathrm{~cm}^{-1}$ [22]. However, the bands at $1036.3 \mathrm{~cm}^{-1}$ were observed after Fenton-like oxidation of $\mathrm{CR}$, conforming the $\mathrm{Fe}-\mathrm{O}$ stretching about $\mathrm{Fe}_{2} \mathrm{O}_{3}$ [21]. The XRD results exposed in Fig. 2c characterize the diffraction patterns of the NMPs. The diffraction peaks at $2 \theta=30.8^{\circ}$ indicate the formation of metals oxides $\left(\mathrm{M}_{\mathrm{x}} \mathrm{O}_{\mathrm{y}}\right)$, where $\mathrm{M}_{\mathrm{x}} \mathrm{O}_{\mathrm{y}}$ may suggest $\mathrm{FeO}, \mathrm{Fe}_{2} \mathrm{O}_{3}, \mathrm{Cu}_{2} \mathrm{O}$, etc. $[23,24]$. The NMPs were observed in crystalline metal oxide phase. The broad metal oxide peak implies that the synthesized NMPs hold a chemically disordered crystal 
Fig. 2 SEM image of NMPs (a) and FTIR analysis of NMPs before and after reaction (b)
Table 1 Energy-dispersive $\mathrm{X}$-ray spectroscopy (EDX) analysis of NMPs
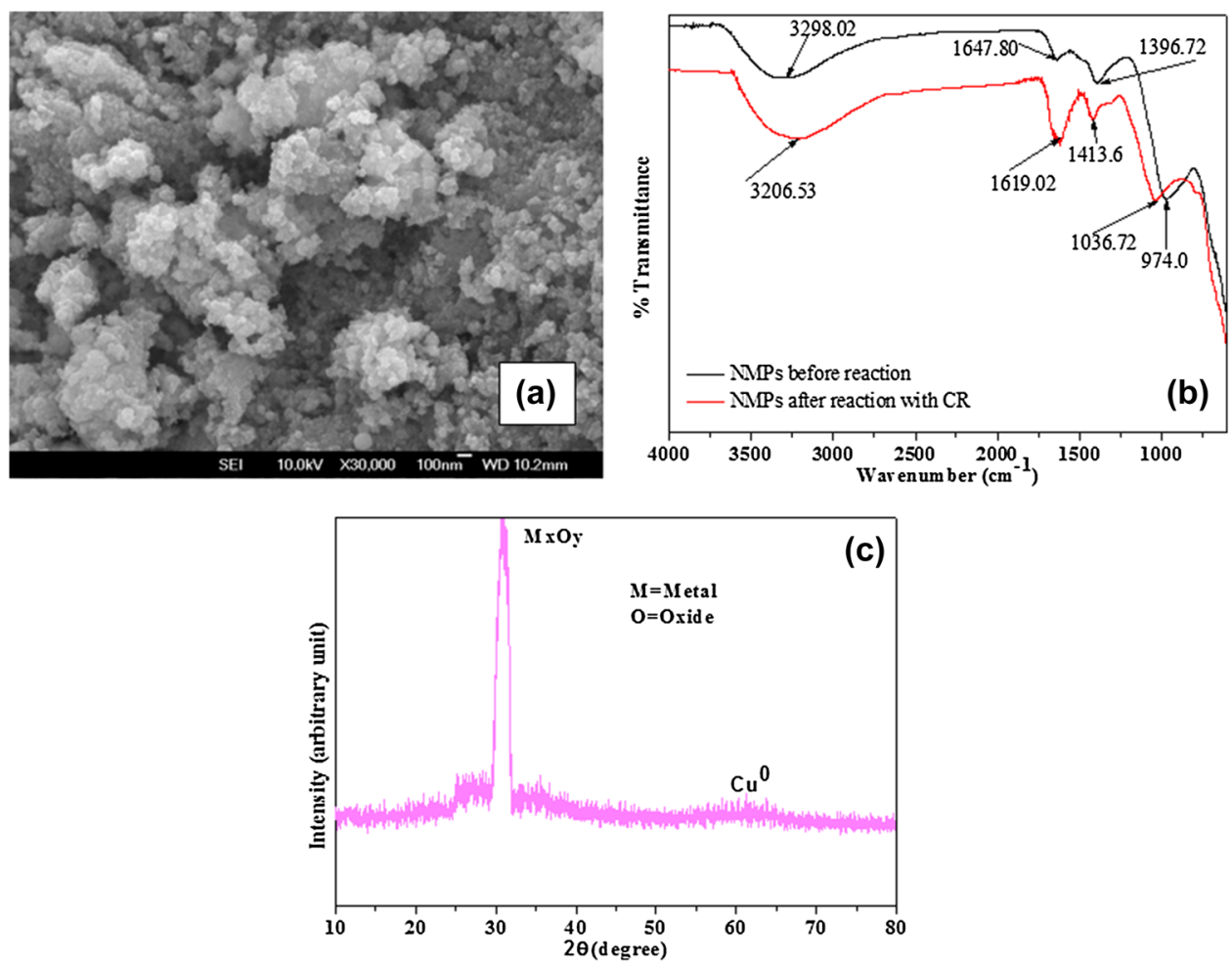

\begin{tabular}{lr}
\hline Element & Weight $(\%)$ \\
\hline $\mathrm{C} \mathrm{K}$ & 26.27 \\
$\mathrm{Al} \mathrm{K}$ & 3.02 \\
$\mathrm{Mn} \mathrm{K}$ & 0.64 \\
$\mathrm{Fe} \mathrm{K}$ & 54.65 \\
$\mathrm{Ni} \mathrm{K}$ & 0.24 \\
$\mathrm{Cu} \mathrm{L}$ & 3.02 \\
$\mathrm{Zn} \mathrm{L}$ & 11.72 \\
Pb M & 0.60 \\
Totals & 100.00 \\
\hline
\end{tabular}

structure [25]. The diffraction peaks at $2 \theta=61.2^{\circ}$ indicate the formation of zero-valent $\mathrm{Cu}$ [26].

\section{Degradation of CR by NMPs}

\section{Effect of NMPs dosages on CR degradation}

The effect of various NMPs dosages $(0.025,0.05,0.10$ and $0.15 \mathrm{~g} / \mathrm{L}$ ) on the reaction rate was carried out at $\mathrm{pH}-3.0$, $\mathrm{CR}$ initial concentration- $10 \mathrm{mg} / \mathrm{L}$, temperature $-25{ }^{\circ} \mathrm{C}$ and concentration of $\mathrm{H}_{2} \mathrm{O}_{2}-50 \mathrm{mM}$ (Fig. 3a). The degradation efficiency of $\mathrm{CR}$ was increased with increasing dosages of NMPs up to $0.10 \mathrm{~g} / \mathrm{L}$, and this happened due to the increasing reaction sites [8]. However, with a further increase in dosages of NMPs, degradation efficiency of CR was reduced gradually. This reduction in the degradation efficiency of CR can be attributed to clustering of NMPs during the reaction [27]. Around $95.8 \%$ of CR degradation efficiency was attained in the $180 \mathrm{~min}$ of reaction time with dose of NMPs of $0.10 \mathrm{~g} / \mathrm{L}$. However, removal efficiency of CR was decreased to $91.9 \%$ with a dose of $0.15 \mathrm{~g} / \mathrm{L}$ of NMPs. A high removal of CR by NMPs might be due to the small size of NMPs resulting high surface area. The CR degradation was increased with the increase in the dose of NMPs; this can be due to more availability of reactive site for electron transfer from the surface NMPs to $\mathrm{H}_{2} \mathrm{O}_{2}$ [28]. The optimum dosage of NMPs was selected as $0.10 \mathrm{~g} / \mathrm{L}$ for subsequent CR degradation. Figure 4a shows the plot of $\mathrm{ln}$ $C_{t} / C_{\mathrm{o}}$ versus $t$ for the degradation of $\mathrm{CR}$ with the different dosages of NMPs. Table 2 shows the values of the pseudofirst-order rate constant $\left(k_{1}\right)$, pseudo-second-order rate constant $\left(k_{2}\right)$ and $R^{2}$ for the degradation of CR with different dosages of NMPs. The value of $k_{1}$ was increased $21.4 \%$ with increasing dose up to $0.10 \mathrm{~g} / \mathrm{L}$. A value of $k_{1}$ was decreased with increasing dose of NMPs; a similar trend was also followed by $k_{2}$ value.

\section{Effect of $p H$ values on $C R$ degradation}

A pH can affect the degradation of organic pollutants by NMPs. Acidic nature of dye solution generating more reactive sites on the surface of NMPs, triggering degradation of organic pollutants. However, an extremely acidic $\mathrm{pH}$ of solution $(\mathrm{pH}<2)$ initiates fast corrosion of NMPs, 

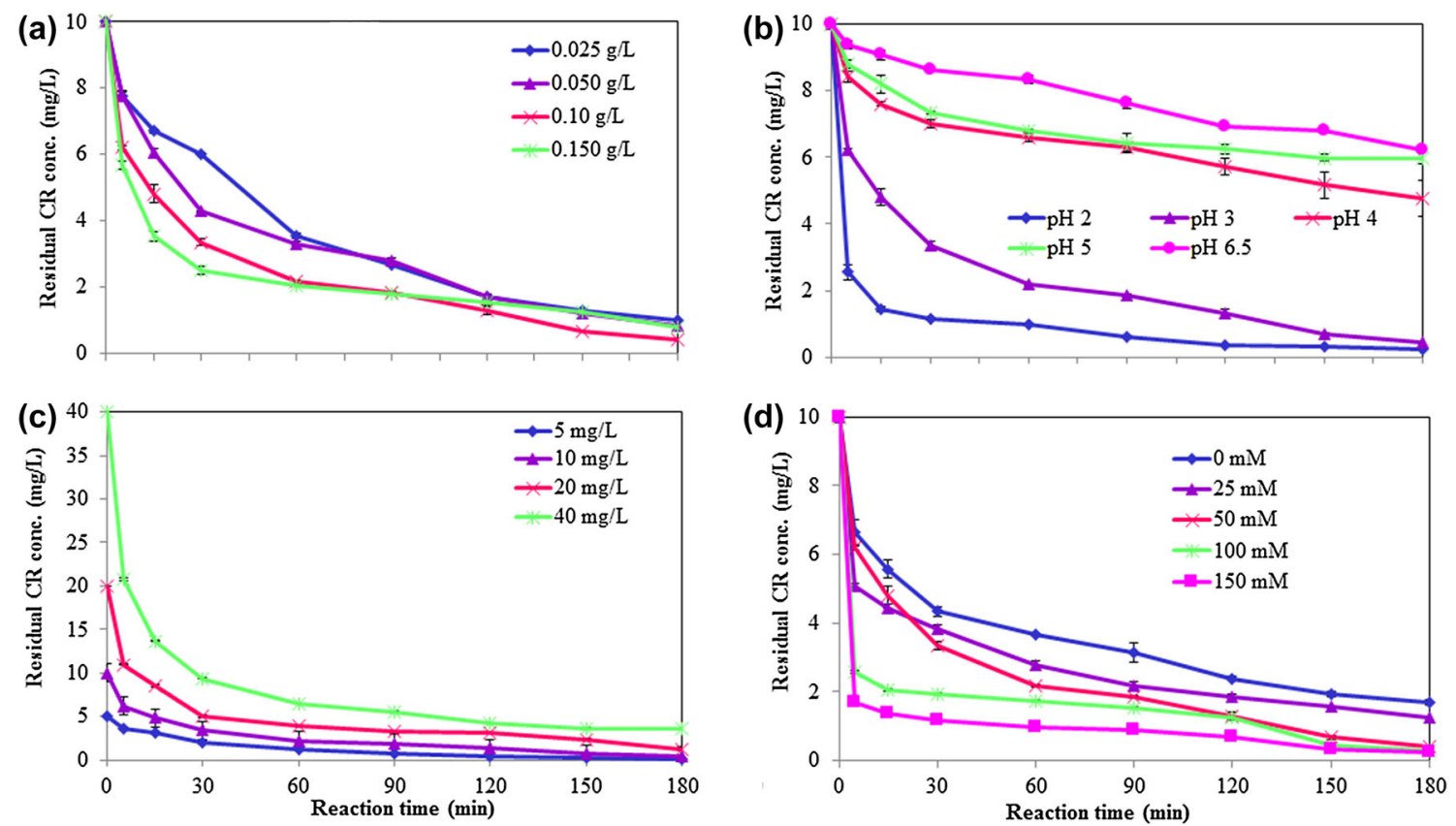

Fig. 3 Effect of the different parameters: effect of dosages of NMPs (a), effects of pH values (b), effect of initial concentration of CR (c) and effect of concentration of $\mathrm{H}_{2} \mathrm{O}_{2}$ (d) on the CR degradation process
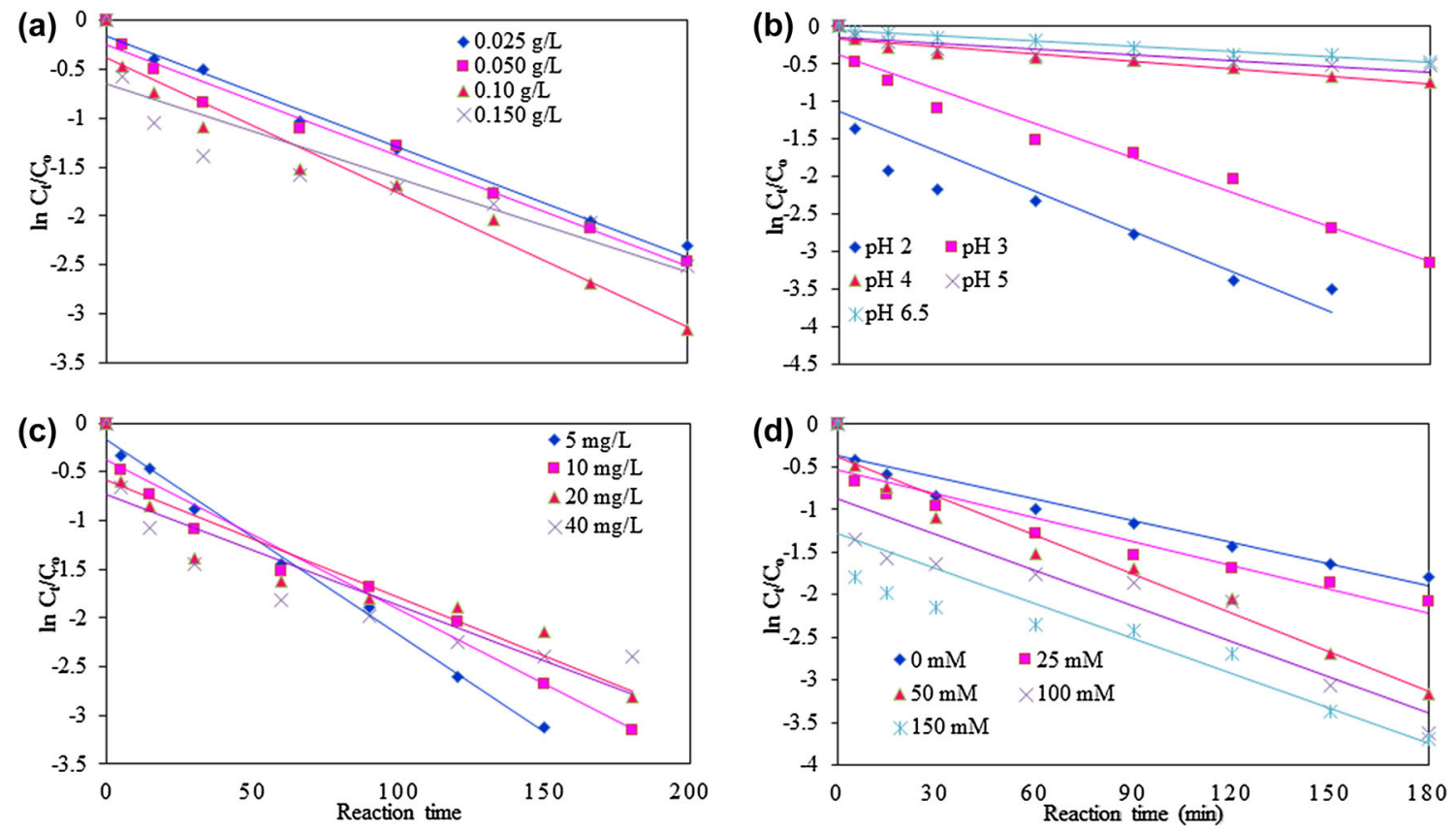

Fig. 4 Kinetic study of CR degradation by NMPs with different parameters: NMPs dose (a), pH values (b), initial concentration of CR (c) and amount of $\mathrm{H}_{2} \mathrm{O}_{2}$ (d)

which can reduce degradation efficiency of pollutants [29]. Many researchers have reported that most of advanced Fenton's processes depend on $\mathrm{pH}$ and acidic conditions, which are favorable to the reaction $[30,31]$. The effects of $\mathrm{pH}$ values ( $\mathrm{pH} 2.0,3.0,4.0,5.0$ and 6.5) on the removal of $\mathrm{CR}$ were studied. The experimental conditions were: dose of NMPs- $0.10 \mathrm{~g} / \mathrm{L}, \mathrm{CR}$ initial concentration-10 $\mathrm{mg} / \mathrm{L}$, temperature $-25{ }^{\circ} \mathrm{C}$ and concentration of $\mathrm{H}_{2} \mathrm{O}_{2}-50 \mathrm{mM}$ (Fig. 3b). The degradation efficiency of $\mathrm{CR}$ was achieved approximately $97.9 \%$ in 180 min of reaction time at $\mathrm{pH}$ of 2.0. The degradation efficiencies of $\mathrm{CR}$ were decreased from 97.9 to $37.8 \%$ with increasing $\mathrm{pH}$ from 2 to 6.5 in a 
Table 2 Kinetic results for CR degradation by NMPs under Fenton-like process

\begin{tabular}{|c|c|c|c|c|c|c|c|}
\hline \multirow[t]{2}{*}{ NMPs dose (g/L) } & \multirow[t]{2}{*}{$C_{0}(\mathrm{CR})(\mathrm{mg} / \mathrm{L})$} & \multirow[t]{2}{*}{ Initial $\mathrm{pH}$} & \multirow[t]{2}{*}{$\mathrm{H}_{2} \mathrm{O}_{2}$ conc. $(\mathrm{mM})$} & \multicolumn{2}{|c|}{ Pseudo-first-order } & \multicolumn{2}{|c|}{ Pseudo-second-order } \\
\hline & & & & $k_{1}\left(\min ^{-1}\right)$ & $R^{2}$ & $k_{2}(\mathrm{~L} / \mathrm{mg} \min )$ & $R^{2}$ \\
\hline 0.025 & 10 & 3.0 & 50 & 0.0126 & 0.9880 & 0.0048 & 0.9611 \\
\hline 0.05 & 10 & 3.0 & 50 & 0.0126 & 0.9754 & 0.0053 & 0.9266 \\
\hline 0.10 & 10 & 3.0 & 50 & 0.0153 & 0.9637 & 0.0104 & 0.8524 \\
\hline 0.15 & 10 & 3.0 & 50 & 0.0107 & 0.8342 & 0.005 & 0.9218 \\
\hline 0.10 & 5 & 3.0 & 50 & 0.0199 & 0.9930 & 0.0414 & 0.7818 \\
\hline 0.10 & 20 & 3.0 & 50 & 0.0120 & 0.8711 & 0.0033 & 0.8481 \\
\hline 0.10 & 40 & 3.0 & 50 & 0.0113 & 0.8036 & 0.0014 & 0.9656 \\
\hline 0.10 & 10 & 2.0 & 50 & 0.0179 & 0.7824 & 0.0229 & 0.9558 \\
\hline 0.10 & 10 & 4.0 & 50 & 0.0034 & 0.9055 & 0.0005 & 0.9514 \\
\hline 0.10 & 10 & 5.0 & 50 & 0.0025 & 0.8163 & 0.0003 & 0.8631 \\
\hline 0.10 & 10 & 6.5 & 50 & 0.0024 & 0.9765 & 0.0003 & 0.9830 \\
\hline 0.10 & 10 & 3.0 & 0 & 0.0085 & 0.9217 & 0.0025 & 0.9842 \\
\hline 0.10 & 10 & 3.0 & 25 & 0.0093 & 0.8790 & 0.0034 & 0.9864 \\
\hline 0.10 & 10 & 3.0 & 100 & 0.0139 & 0.8036 & 0.0151 & 0.7352 \\
\hline 0.10 & 10 & 3.0 & 150 & 0.0136 & 0.7308 & 0.0174 & 0.8588 \\
\hline
\end{tabular}

reaction time of $180 \mathrm{~min}$; this can be due to the decrease in activity of the NMPs [32]. Figure $4 \mathrm{~b}$ shows the plot of $\ln$ $C_{t} / C_{\mathrm{o}}$ versus $t$ for the removal of $\mathrm{CR}$ with the various values of $\mathrm{pH}$. The values of $k_{1}$ and $k_{2}$ were reduced around 86.6 and $98.7 \%$, respectively, when the value of $\mathrm{pH}$ was increased from 2.0 to 6.5 (Table 2). Remarkably, rapid degradation of $\mathrm{CR}$ was detected at $\mathrm{pH} 2.0$ of $\mathrm{CR}$ solution. The results also stated that reaction rate was decreased with increasing $\mathrm{pH}$ values, and the oxides of metals were available on the surfaces of NMPs, which were rapidly dissolved in acidic solution and the active sites are free and enhancing corrosion of metals including Fe [8]. At pH 2 of solution, more hydroxyl radicals were generated, which caused the very fast degradation of $\mathrm{CR}$ [27]. At $\mathrm{pH} 4,5$ and 6.8 limited the removal of CR was achieved due to the low concentration of $\mathrm{H}^{+}$occurs in the solution, consequentially low generation of hydroxyl radicals. Furthermore, metals hydroxides are generated with the increase in the $\mathrm{pH}$ from 4 to 6.8 during the reaction. The accumulation of metal hydroxide precipitates on the surface of NMPs will hinder the generation of reactive oxygen species and decrease the MB removal [28].

\section{Effect of initial concentrations of $C R$ on the degradation of $C R$}

Figure $3 \mathrm{c}$ shows the effect of initial CR concentrations (5, 10,20 and $40 \mathrm{mg} / \mathrm{L}$ ) on the degradation rate under the following experimental conditions: dose of NMPs- $0.10 \mathrm{~g} /$ $\mathrm{L}$, initial $\mathrm{pH}-3.0$, temperature $-25^{\circ} \mathrm{C}$ and concentration of $\mathrm{H}_{2} \mathrm{O}_{2}-50 \mathrm{mM}$. Degradation efficiency of $\mathrm{CR}$ was decreased from 97.9 to $91.0 \%$ with an increasing initial concentration from 5 to $40 \mathrm{mg} / \mathrm{L}$. The active sites of NMPs were occupied by an increasing $\mathrm{CR}$ concentration. Figure $4 \mathrm{c}$ demonstrates the plot of $\ln C_{t} / C_{\mathrm{o}}$ versus $t$ for degradation of $\mathrm{CR}$ with the different concentrations of CR. The values of $k_{1}$ and $k_{2}$ were decreased around 43.2 and $96.6 \%$, respectively, with increasing initial CR concentrations from 5 to $40 \mathrm{mg} / \mathrm{L}$. Reduction in the rate of degradation of $\mathrm{CR}$ with high concentration of dye may be due to the adsorption of dye molecule on the surface of NMPs, and it could occupy the active sites of NMPs [27]. The values of $k_{1}, k_{2}$ and $R^{2}$ for the degradation rate of $\mathrm{CR}$ with various concentrations of $\mathrm{CR}$ are given in Table 2 . The slow degradation of $\mathrm{CR}$ after $60 \mathrm{~min}$ of reaction time may be clarified by the difficulty in changing the $N$ atoms of the $\mathrm{CR}$ into oxidized nitrogen compounds and the slow reaction of short chain aliphatics with hydroxyl radicals; furthermore, the higher number of azo-groups in dye molecule decreases the degradation process [33].

\section{Effect of the $\mathrm{H}_{2} \mathrm{O}_{2}$ addition on $\mathrm{CR}$ degradation}

As shown in Fig. 3d, the effect of $\mathrm{H}_{2} \mathrm{O}_{2}$ concentrations $(0$, $25,50,100$ and $150 \mathrm{mM}$ ) on the degradation rate was studied under the following experimental condition: dose of NMPs- $0.10 \mathrm{~g} / \mathrm{L}, \mathrm{pH}$ value -3.0 , temperature- $25^{\circ} \mathrm{C}$ and initial concentration of $\mathrm{CR}-10 \mathrm{mg} / \mathrm{L}$. The $\mathrm{CR}$ degradation rate was found to be low with NMPs and without addition of $\mathrm{H}_{2} \mathrm{O}_{2}$; this is because of insufficient or 
Table 3 Comparative study for the degradation of CR by different nanomaterials

\begin{tabular}{|c|c|c|c|c|}
\hline Nano materials applied & Method of degradation & Reaction time (mins) & Removal (\%) & References \\
\hline $\mathrm{ZnO}-\mathrm{Pd}$ & Photocatalytic & 180 & 100 & {$[35]$} \\
\hline $\mathrm{CuO}$, nano-rod & Photocatalytic & 210 & 67 & {$[36]$} \\
\hline Carissa edulis extract capped & Photocatalytic & 130 & 97 & [37] \\
\hline \multicolumn{5}{|l|}{$\mathrm{ZnO}$ nanoparticles } \\
\hline $\mathrm{ZnO}$ & Photocatalytic & 80 & 95.02 & [38] \\
\hline $\mathrm{TiO}_{2}$ & Photocatalytic & 30 & 93.9 & [39] \\
\hline $\mathrm{Fe}_{3}+/\left(\mathrm{NH}_{4}\right)_{2} \mathrm{~S}_{2} \mathrm{O}_{8} / \mathrm{UV}$ & Photo-Fenton process & 50 & 100 & {$[40]$} \\
\hline NMPs & Advanced Fenton's process & 180 & 99.8 & Present study \\
\hline
\end{tabular}

no creation of hydroxyl radicals during the reaction. The hydroxyl radical is one of the most strongest oxidizing agents, which attacks organic compounds present at the surface of the NMPs [27]. The CR removal efficiency was increased from 83.2 to $95.8 \%$ by increasing the concentration of $\mathrm{H}_{2} \mathrm{O}_{2}$ from 0 to $50 \mathrm{mM}$; this is due to the generation of huge amount of hydroxyl radicals [27]. However, with a further increase in the concentration of $\mathrm{H}_{2} \mathrm{O}_{2}$, degradation efficiency was decreased slightly; this can be attributed to recombination of hydroxyl radicals and scavenging effect of $\mathrm{H}_{2} \mathrm{O}_{2}$, causing decrease in the oxidation of NMPs by $\mathrm{H}_{2} \mathrm{O}_{2}$ [14]. Furthermore, hydroperoxyl radicals were generated from the excess hydroxyl radicals, which were not participated in the oxidative degradation of the CR due to very less reactivity of hydroperoxyl radicals. The degradation of the CR was found by mainly reaction with hydroxyl radicals [1]. Figure $4 d$ displays the plot of $\ln$ $C_{t} / C_{\mathrm{o}}$ versus $t$ for the degradation of $\mathrm{CR}$ with various concentrations of $\mathrm{H}_{2} \mathrm{O}_{2}$. The value of $k_{1}$ was increased around $80 \%$ with an increasing concentration of $\mathrm{H}_{2} \mathrm{O}_{2}$ up to $50 \mathrm{mM}$. However, with further increase in the concentration of $\mathrm{H}_{2} \mathrm{O}_{2}$, a value of $k_{1}$ was slightly reduced. However, the value of $k_{2}$ was increased with increasing concentration of $\mathrm{H}_{2} \mathrm{O}_{2}$ from 0 to $150 \mathrm{mM}$. The removal efficiency of CR was enhanced suggestively in the combination of NMPs and hydrogen peroxide in acidic $\mathrm{pH}$ of solution as compared to the NMPs alone. Table 2 shows the values of $k_{1}$, $k_{2}$ and $R^{2}$ for the degradation rate of $\mathrm{CR}$ with various concentrations of $\mathrm{H}_{2} \mathrm{O}_{2}$.

\section{Probable mechanism for the removal of CR by NMPs}

The oxidation of CR by hydroxyl radicals was mainly responsible for the degradation of $\mathrm{CR}$ in an aqueous solution. Hydroxyl radicals are generated when NMPs can react with the aqueous $\mathrm{H}_{2} \mathrm{O}_{2}$ [28]. The highest rate of $\mathrm{CR}$ degradation may be due to the high corrosion of NMPs at acid $\mathrm{pH}$ of solution and availability of numerous active sites for reaction. An oxidation of $\mathrm{CR}$ by $\mathrm{H}_{2} \mathrm{O}_{2}$ in the acidic $\mathrm{pH}$ of solution was mainly due to the generation of hydroxyl radicals in the reaction [34]. The removal mechanism of CR using NMPs can be expressed as follows [14]:

$\mathrm{NMPs}+\mathrm{H}_{2} \mathrm{O}_{2}+\mathrm{H}^{+} \rightarrow \mathrm{M}^{\mathrm{n}+}+\mathrm{OH}^{-}+\mathrm{OH}^{-}$

$\mathrm{M}^{n+}+\mathrm{H}_{2} \mathrm{O}_{2} \rightarrow \mathrm{M}^{(\mathrm{n}+1)+} \rightarrow \mathrm{OH}^{-}+\mathrm{OH}^{-}$

$\mathrm{OH}+\mathrm{CR} \rightarrow$ Intermediate $+\mathrm{CO}_{2}+\mathrm{H}_{2} \mathrm{O}$

$\mathrm{M}_{\mathrm{x}} \mathrm{O}_{\mathrm{y}}+\mathrm{nH}^{+} \rightarrow \mathrm{nM}^{\mathrm{n}+}+\mathrm{nH}_{2} \mathrm{O}$

where "M" represents metal, " $n$ " is number of valences or moles, and "O" represents oxides.

The studies on degradation of Congo red have been represented in Table 3. When NMPs compared with all other catalyst showed almost highest $\%$ degradation than other materials such as Carissa edulis extract capped $\mathrm{ZnO}$, $\mathrm{ZnO}$ and $\mathrm{TiO}_{2}$ nanoparticles.

\section{Conclusion}

The degradation of CR by NMPs in the presence of $\mathrm{H}_{2} \mathrm{O}_{2}$ was found to be highly effective. The $\mathrm{CR}$ degradation efficiencies were increased from 90.1 to $95.8 \%$ with increasing the dosages of NMPs from 0.025 to $0.10 \mathrm{~g} / \mathrm{L}$ and further increase in dosages, efficiency was not increased. However, degradation efficiency was decreased from 97.9 to $37.8 \%$ with increasing the value of $\mathrm{pH}$ from 2.0 to 6.5. The degradation efficiency of CR was reduced with an increasing concentration of CR. However, degradation efficiency was increased with an increasing concentration of $\mathrm{H}_{2} \mathrm{O}_{2}$ up to certain limit. The degradation efficiency of CR by NMPs was most suitable under acidic $\mathrm{pH}$ of solution. The degradation of CR by NMPs under Fenton-like process followed the pseudo-second-order kinetics as compared to the pseudo-second-order kinetics. A very fast degradation rate was attained at $\mathrm{pH} 2.0$ of $\mathrm{CR}$ solution. The present study confirmed that the CR can be removed successfully by even very small amount of NMPs under the Fenton-like process. 
Acknowledgements This study has been conducted by the research grant of Kwangwoon University in 2017. This work was also supported by the UGC-BSR Research startup grant (No. F. 30-382/2017, BSR), Government of India.

\section{References}

1. Kondru AK, Kumar P, Chand S (2009) Catalytic wet peroxide oxidation of azo dye (Congo red) using modified $\mathrm{Y}$ zeolite as catalyst. J Hazard Mater 166:342-347

2. Sha Y, Mathew I, Cui Q, Clay M, Gao F, Zhang XJ, Gu Z (2016) Rapid degradation of azo dye methyl orange using hollow cobalt nanoparticles. Chemosphere 144:1530-1535

3. Li P, Song Y, Wang S, Tao Z, Yu S, Liu Y (2015) Enhanced decolorization of methyl orange using zero-valent copper nanoparticles under assistance of hydrodynamic cavitation. Ultrason Sonochem 22:132-138

4. Goudarzi M, Bazarganipour M, Salavati-Niasari M (2014) Synthesis, characteriza-tion and degradation of organic dye over $\mathrm{Co}_{3} \mathrm{O}_{4}$ nanoparticles prepared from new binuclear complex precursors. RSC Adv 4(87):46517-46520

5. Manivel A, Lee G-J, Chen C-Y, Chen J-H, Ma S-H, Horng T-L, Wu JJ (2015) Synthesis of $\mathrm{MoO}_{3}$ nanoparticles for azo dye degradation by catalytic ozonation. Mater Res Bull 62:184-191

6. Nidheesh P, Gandhimathi R, Ramesh S (2013) Degradation of dyes from aqueous solution by Fenton processes: a review. EnvironSci Pollut Res 20(4):2099-2132

7. Singla P, Sharma M, Pandey OP, Singh K (2014) Photocatalytic degradation of azo dyes using $\mathrm{Zn}$-dopedand undoped $\mathrm{TiO}_{2}$ nanoparticles. Appl Phys A 116(1):371-378

8. Fang ZQ, Qiu XQ, Chen JH, Qiu XH (2010) Degradation of metronidazole by nanoscale zero-valent metal prepared from steel pickling waste liquor. Appl Catal B Environ 100:221-228

9. Shih Y-H, Tso C-P, Tung L-Y (2008) Rapid degradation of methyl orange with nanoscale zerovalent iron particles. Nanotechnology 7:16-17

10. Bokare AD, Chikate RC, Rode CV, Paknikar KM (2008) Ironnickel bimetallic nanoparticles for reductive degradation of azo dye Orange $\mathrm{G}$ in aqueous solution. Appl Catal B Environ 79(3):270-278

11. Rani S, Sumanjit K, Mahajan RK (2016) Synthesis of mesoporous material SBA-3 for adsorption of dye congo red. Desalination Water Treat 57(8):3720-3731

12. Kaur S, Rani S, Kumar V, Mahajan RK, Asif M, Tyagi I, Gupta VK (2015) Synthesis, characterization and adsorptive application of ferrocene based mesoporous material for hazardous dye Congo red. J Ind Eng Chem 26:234-242

13. Sumanjit Seema, Mahajan RK, Gupta VK (2015) Modification of surface behaviour of Eichhornia crassipes using surface active agent: an adsorption study. J Ind Eng Chem 21:189-197

14. Singh J, Yang JK, Chang YY (2016) Rapid degradation of phenol by ultrasound-dispersed nano-metallic particles (NMPs) in the presence of hydrogen peroxide: a possible mechanism for phenol degradation in water. J Environ Manage 175:60-66

15. Singh J, Lee BK (2015) Pollution control and metal resource recovery for low grade automobile shredder residue: a mechanism, bioavailability and risk assessment. Waste Manage 38:271-283

16. Singh J, Yang JK, Chang YY (2016) Quantitative analysis and reduction of the eco-toxicity risk of heavy metals for the fine fraction of automobile shredder residue (ASR) using $\mathrm{H}_{2} \mathrm{O}_{2}$. Waste Manage 48:374-382

17. Singh J, Lee BK (2015) Reduction of environmental availability and ecological risk of heavy metals in automobile shredder residues. Ecol Eng 81:76-81
18. Rasheed QJ, Pandian K, Muthukumar K (2011) Treatment of petroleum refinery wastewater by ultrasound-dispersed nanoscale zero-valent iron particles. Ultrason Sonochem 18:1138-1142

19. Singh J, Lee BK (2015) Hydrometallurgical recovery of heavy metals from low-grade automobile shredder residue (ASR): an application of an advanced Fenton process (AFP). J Environ Manage 161:1-10

20. Fang ZQ, Qiu XH, Chen JH, Qiu XQ (2011) Debromination of polybrominated diphenyl ethers by $\mathrm{Ni} / \mathrm{Fe}$ bimetallic nanoparticles: influencing factors, kinetics, and mechanism. J Hazard Mater 185:958-969

21. Zha SX, Cheng Y, Gao Y, Chen ZL, Megharaj M, Naidu R (2014) Nanoscale zerovalent iron as a catalyst for heterogeneous Fenton oxidation of amoxicillin. Chem Eng J 255:141-148

22. Yuan SJ, Dai XH (2014) Facile synthesis of sewage sludgederived mesoporous material as an efficient and stable heterogeneous catalyst for photo-Fenton reaction. Appl Catal B Environ 154-155:252-258

23. Singh J, Lee BK (2016) Recovery of precious metals from lowgrade automobile shredder residue: a novel approach for the recovery of nano zero-valent copper particles. Waste Manage 48:353-365

24. Zhou JY, Yu XJ, Ding C, Wang ZP, Zhou QQ, Pao H, Cai WM (2011) Optimization of phenol degradation by Candida tropicalis Z-04 using Plackette Burman design and response surface methodology. J Environ Sci 23:22-30

25. Fan J, Guo Y, Wang J, Fan M (2009) Rapid decolorization of azo dye methyl orange in aqueous solution by nanoscale zerovalent iron particles. J Hazard Mater 166:904-910

26. Chen H-L, Chiang T-H, Wu M-C (2012) Evolution of morphology of nano-scale $\mathrm{CuO}$ grown on copper metal sheets in $5 \mathrm{wt} \%$ $\mathrm{NaCl}$ solution of spray fog environment. J Surf Eng Mater Adv Technol 2:278-283

27. Xu L, Wang J (2011) A heterogeneous Fenton like system with nanoparticulate ZVI for removal of 4 chloro 3 methyl phenol. J Hazard Mater 186:256-264

28. Cheng Z, Fu F, Pang Y, Tang B, Lu J (2015) Removal of phenol by acid-washed zero-valent aluminium in the presence of $\mathrm{H}_{2} \mathrm{O}_{2}$. Chem Eng J 260:284-290

29. Tian H, Li JJ, Mu Z, Li LD, Hao ZP (2009) Effect of pH on DDT degradation in aqueous solution using bimetallic $\mathrm{Ni} / \mathrm{Fe}$ nanoparticles. Sep Purif Technol 66(1):84-89

30. Bokare AD, Choi W (2009) Zero-valent aluminum for oxidative degradation of aqueous organic pollutants. Environ Sci Technol 43:7130-7135

31. Liu WP, Zhang HH, Cao BP, Lin K, Gan J (2011) Oxidative removal of bisphenol A using zero valent aluminum-acid system. Water Res 45:1872-1878

32. Babuponnusami A, Muthukumar K (2012) Removal of phenol by heterogeneous photo electro Fenton-like process using nano-zero valent iron. Sep Purif Technol 98:130-135

33. Ljubas D, Smoljani G, Jureti H (2015) Degradation of methyl orange and congo red dyes by using $\mathrm{TiO}_{2}$ nanoparticles activated by the solar and the solar-like radiation. J Environ Manage 161:83-91

34. Yang S, Wang $P$, Yang $X$, Shan L, Zhang W, Shao X, Niu R (2010) Degradation efficiencies of azo dye acid orange 7 by the interaction of heat, UV and anions with common oxidants: persulfate, peroxymonosulfate and hydrogen peroxide. J Hazard Mater 179:552-558

35. Rokesh K, Pandikumar A, Jeganathan K, Jothivenkatachalam K (2016) Zinc oxide nanostructures and their morphology depended optical, crystalline and photocatalytic properties. Mater Focus $5: 385-392$

36. Sadollahkhani A, Ibupoto ZH, Elhag S, Nur O, Willander M (2014) Photocatalytic properties of different morphologies of 
$\mathrm{CuO}$ for the degradation of Congo red organic dye. Ceram Int 40:11311-11317

37. Fowsiya J, Madhumitha G, Al-Dhabi NA, Arasu MV (2016) Photocatalytic degradation of Congo red using Carissa edulis extract capped zinc oxide nanoparticles. J Photochem Photobiol B 162:395-401

38. Laouedj EN, Ahmed B (2011) ZnO assisted photocatalytic degradation of Congo red and Benzopurpurine 4B in aqueous solution. Chem Eng Process Technol 2:1-9
39. Erdemoglu S, Aksu SK, Sayilkan F, Izgi B, Asiltürk M, Sayilkan H, Frimmel F, Güçer S (2008) Photocatalytic degradation of Congo Red by hydrothermally synthesized nanocrystalline $\mathrm{TiO}_{2}$ and identification of degradation products by LC-MS. J Hazard Mater 155:469-476

40. Gomathi Devi L, Girish Kumar S, Mohan Reddy K (2009) Photo fenton like process $\mathrm{Fe}_{3}+/\left(\mathrm{NH}_{4}\right)_{2} \mathrm{~S}_{2} \mathrm{O}_{8} / \mathrm{UV}$ for the degradation of Di azo dye congo red using low iron concentration. Cent Eur $\mathbf{J}$ Chem 7(3):468-477 